\title{
AIR POLLUTION AND CLIMATE CHANGE IN LAGOS, NIGERIA: NEEDS FOR PROACTIVE APPROACHES TO RISK MANAGEMENT AND ADAPTATION
}

\author{
Akinola A. Komolafe, Suleiman Abdul-Azeez Adegboyega, Adeleye Y.B. Anifowose, \\ Francis Omowonuola Akinluyi and Dauda Rotimi Awoniran \\ Department of Remote Sensing and Geoscience Information System, \\ Federal University of Technology, Akure, Nigeria
}

Received 2014-02-24; Revised 2014-07-08; Accepted 2014-07-12

\begin{abstract}
The significance of air pollution as one of the contemporary issues and accelerating factors that propel climate change in both developed and developing countries cannot be overemphasized. The problem of air pollution has seemingly become intractable with the incessant failure of both global and local environmental policies purportedly emplaced to address its devastating trend, particularly in growing megacities of the world. The devastating effects of the phenomenon are more pronounced in megacities of developing countries than in developed ones. Lagos, as an industrialized, commercialized and an emerging megacity in Nigeria, has been subjected to several predictions of the negative impacts of changing climatic conditions partly caused by ubiquitous air pollution. Efforts at stemming the tide of the increasing challenges of air pollution worldwide has significantly been thwarted by inadequate funding, hence the need to review the literature on the environmental implications of growing air pollution, its contributions to climate change and its negative impacts on the lives and properties of teeming inhabitants of Lagos. A review like this will provide a synthesis of knowledge and information on mitigative and adaptive measures that can be adopted to minimize the impacts of air pollution on the mega city.This study utilizes consciously selected and current literatures on the subject matter and found that Lagos inhabitants have been vulnerable to virtually all forms of damaging effects of climate change majorly propelled by seemingly uncontrollable air pollution. This implies that the situation requires proactive measures, otherwise, avoidable loss of lives and large scale destruction of properties may be inevitable. The paper therefore advocates involvement of all stakeholders in both mitigation and adaptation measures to climate change through enhancement of indigenous knowledge and creation of awareness among citizens about the need to be conscious of their carbon foot prints.
\end{abstract}

Keywords: Air Pollution, Climate Change, Carbon Foot Prints, Environmental Policies

\section{INTRODUCTION}

The process of urbanization is mostly associated with many environmental challenges with adverse effects on the living standard of people. Urban areas of the world are often confronted with the challenge of population due to unceasing migration of people from rural areas to urban areas to enhance their living standards through job seeking, businesses and trading. Most times the aspirations of people from rural areas are often met with obstacles such as housing, competition for existing dwellers, paucity of jobs and exposure to disasters resulting from overpopulation (Phillips and Horwood, 2007). The population increase results in skyrocketing demands for housing that culminate in the city expansion with attendant industrialization and infrastructural development that need proper environmental policy measure to avoid dangerous effects on the environment. In most developing

Corresponding Author: Akinola A. Komolafe, Department of Remote Sensing and Geoscience Information System, Federal University of Technology, Akure, Nigeria 
countries, the environmental impacts of urbanization are enormous; the most common of these being air pollution. The subject of air pollution and its effects on the environment is referred to as one of the Universal Commons that many countries and local governments are seeking to address (Puppim de Oliveira, 2011). Air pollution is one of the environmental problems confronting growing cities and is currently the challenge faced by many developed and developing countries; its effects on human lives are enormous as it causes disease and can result in chronic illness. Apart from the health risk, it contributes to our changing climatic conditions, which are potential sources of threats to local and international communities.

The current global changes caused by the changing climate have been attributed to human activities (Crowley, 2000) through civilization and industrialization and it is interesting to know that the urban settlements where most industrial activities occur in the world are also direct and indirect sources of global challenges. Our atmospheric environment is very sensitive to various types of pollution resulting from three phenomena: Global warming, ozonelayer depletion and, above all, local air pollution. The latter, which is mostly anthropogenic in nature, results from industrial activities, fossil fuel generator fumes, chemical exposures and so on. The pollutant molecules such as Sulphur Oxides $\left(\mathrm{SO}_{\mathrm{x}}\right)$, Nitrogen Oxides $\left(\mathrm{NO}_{\mathrm{x}}\right)$ Lead, Ozone, Benzene, Carbon Oxides $\left(\mathrm{CO}_{\mathrm{x}}\right)$ Arsenic, $\mathrm{Cd}, \mathrm{Hg}$ and Particulate Matters have negative effect on the human health, which can rapidly spread abroad causing health instability in the system. When the concentrations of these molecules/particles in the air exceed the international standard, the air is considered polluted. Concentration of these pollutants, carbon dioxide and nitrogen oxides, directly contributes to climate change which has become one of the world's challenges today. High concentrations of carbon in the atmosphere increase the climatic temperatures, causes greenhouse warming which often result in the heat generated from the sun being trapped close to the surface of the Earth. Increased concentrations of heat in the atmosphere over the years lead to precipitation, rise in sea level and subsequent unusual rainfall that cause flooding in most vulnerable areas.

The continuous expansion, population increase and transformation of Lagos City, one of most industrialized cities in the world have contributed to its present polluted states. It is obvious that increasing human activities, especially greenhouse gas emissions are posing great environmental challenges that have resulted in loss of lives and destruction of properties in the state (Olowoporoku et al., 2012). The effects of NOx on the level of ozone pollution and the subsequent respiratory problem among children and adults in Nigeria have been reported by (Raheem and Adekola, 2011).

The overall effects of air pollution on Lagos citizens and environments contribute to drag in the efforts for its most sustainable programs. Major sources of gas emission in Lagos are dump sites, open incinerators and power generators. The relationship between the air pollutants and the current climate change effects on Lagos need to be established in order to guide against future consequences.

\section{THE STUDY AREA}

Lagos is Nigeria's most cosmopolitan city and most over-populated with an estimated population of $21,200,000$ people especially migrants from the hinterland. It has a total area of 3,577.28 square kilometers, with wetland consisting of about $22 \%$ of the area; and a population density of 5,926 persons per square kilometer (Oshodi, 2013). It was originated on the islands separated by creeks such as Lagos Island, protected from the Atlantic Ocean by sand spits like the Bar Beach (Fig. 1). Lagos is the largest city in Nigeria. It is the main city of Lagos State and Nigeria's main commercial centre, with more than $70 \%$ of the nation's industries and economic activities. The city is also important to the rest of West Africa as a leading regional port and manufacturing centre with the highest number of multinational companies (Phillips and Horwood, 2007). The land mass of Lagos is almost occupied by both residential and industrial land uses, creating a congested environment for the people. Lagos accounts for about $40 \%$ of new vehicle registrations in Nigeria and it is the most industrialized with greenhouse gas emission.

\section{SOURCES OF AIR POLLUTION IN LAGOS STATE}

The continuous expansion, population increase and transformation of the Lagos city, one of the most industrialized cities in the world have contributed to its present polluted states. It is obvious that the increasing human activities, especially greenhouse gas emissions are posing great environmental challenges that have resulted in loss of lives and destruction of properties in the state. The overall effects of air pollution on Lagos Citizens and environments contribute to drag in the efforts for its most sustainable programs.

Sources of gas emission in Lagos are dump sites, open incinerators and power generators. Other notable sources of air pollution are the vehicular emission due to the increase in vehicles, industrial and commercial buses; the use of chemicals, wastes and fossil fuel burning emanating from industries (Fig. 2). 


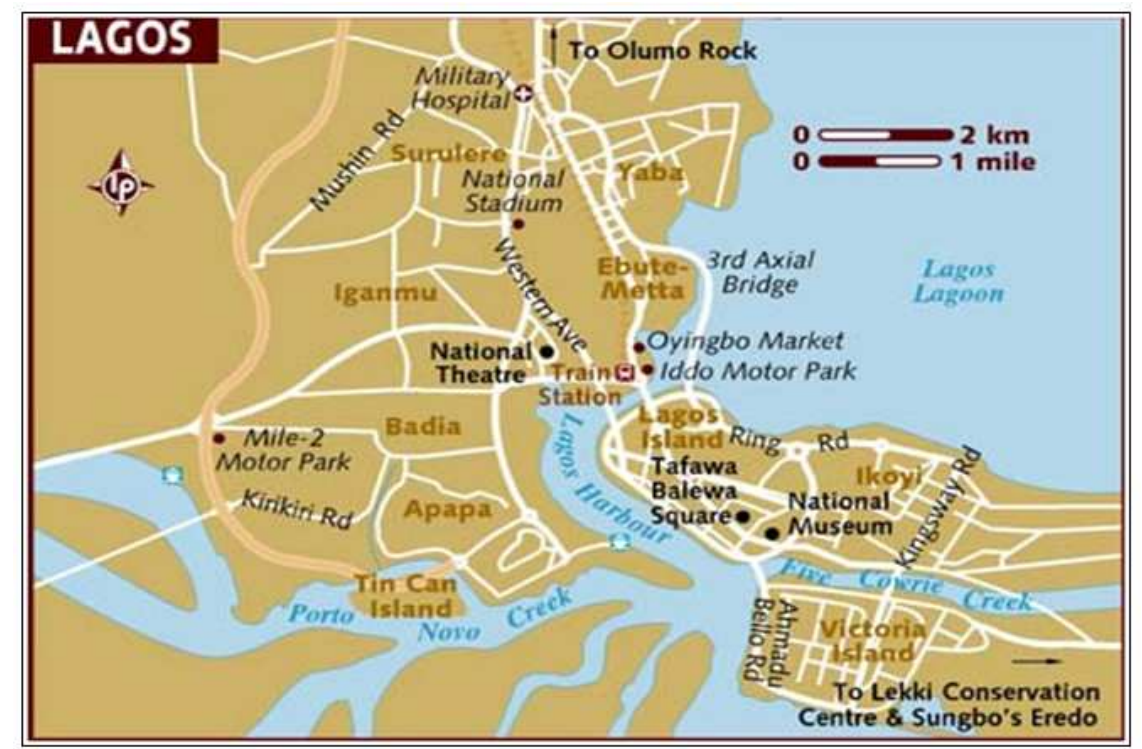

Fig. 1. Map of Lagos, Nigeria (Source: Lonely planet)
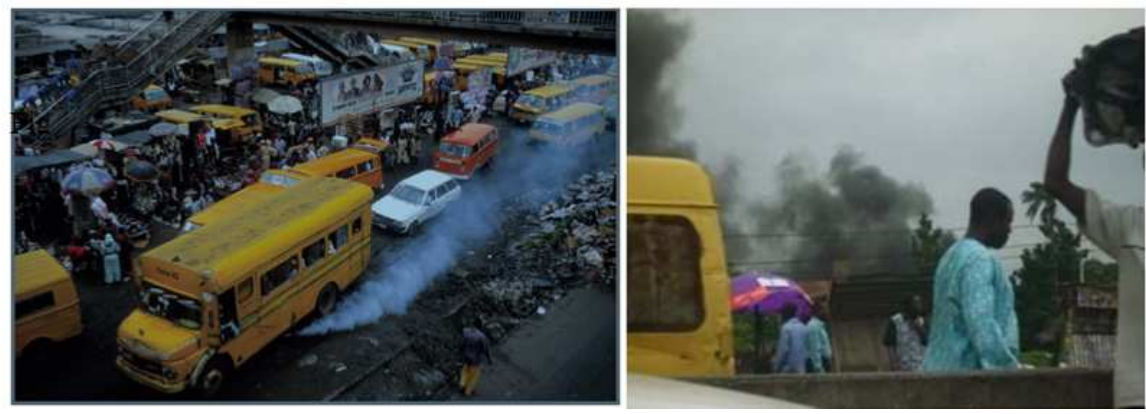

Fig. 2. Pollution arising from various vehicles and fossil fuel burning in Lagos States (Phillips and Horwood, 2007)

\subsection{Manufacturing Industries}

In terms of development and industrial infrastructure Lagos is one of the fastest growing mega cities in the world. (Kotkin and Cox, 2013). Over $70 \%$ of the industries in Nigeria, consisting of more than 7,000 medium and large scale manufacturing industries are located in the city. The industrial sectors in Lagos, based on the Manufacturer's Association of Nigeria (MAN) grouping, are food, beverage and tobacco; textile, wearing apparel; pulp and paper products; chemical and pharmaceutical; wood and wood products; non-metallic mineral products; basic metal; electrical and electronic; motor vehicle and miscellaneous; and domestic and industrial plastics (MAN, 1991). Manufacturing industries in Lagos State have either wet processes or dry processes or both and each has its respective environmental impact and contributes significantly to the effects of Climate Change. Manufacturing operations that are most likely to be affected by climate change regulations are those that result in significant direct Greenhouse Gas Emissions (GHG), such as cement, iron and steel production, as well as those that are highly energy intensive, such as paper and chemicals operations. Many manufacturing industries in Lagos still rely on Hydroelectric Power Supply which is epileptic and consequently increased the use of power generating sets, thus more carbon emissions. About $60 \%$ of total non-oil enterprises in Nigeria are located in the Lagos State, which makes it most important industrial city in the Economic Community of West African States (ECOWAS) sub-region. Being the highest consumer of 
energy, which is predominantly fossil-based, makes it one of the largest contributors to carbon-dioxide emissions in the country at large. It is therefore pertinent that emission reduction strategies must take cognizance of the large manufacturing and industrial presence in the State.

\subsection{Vehicular Emissions}

The urban transport sector is a major source of air and noise pollution in Metropolitan Lagos.

After manufacturing of goods, poor transportation system and lack of credible alternative to road transportation has resulted in more vehicles and greater emissions from diesel engines. Transportation of manufactured goods involves the use of trucks and heavy duty vehicles that add to the pollution load and release of Carbon into the environment. Studies have shown that in Lagos State Vehicular Emissions are the highest point source contributors of carbon dioxide into the environment, followed by the manufacturing industries. Unending traffic jams in Lagos metropolis results in commuters spending several unproductive hours in traffic and increased avoidable emissions of carbondioxide and other pollutants. A study conducted by the Lagos Metropolitan Transport Management Authority (LAMATA) on air quality between 2003 and 2007 indicated that vehicles contribute approximately $43 \%$ ambient air pollution in Lagos. The study recognized the transport sector as the fastest growing source of Green House Gases. Over 50\% of the transport sector contribution to GHG emission in Nigeria comes from Lagos alone. Large volumes of traffic, electricity generating plants and facilities, wastes generated from different sources, pollutants and pollutions of the air, water and land, landfills, poor management and others resulted in the presence of these oxides, particulates and the reactions, (Akanni, 2010; Emordi and Osiki, 2008; Ogunnowo and Aderogba, 2006). Other noticeable changes are found in the:-Total amount of rainfall per annum that is slightly increased but the spread per year and intensities have reduced and other forms of precipitation have reduced; and-Cloud covers appear to have increased.

\subsection{Waste Management}

Waste discharge and wastewater treatment are sources of greenhouse gas emissions. Although Carbon Dioxide $\left(\mathrm{CO}_{2}\right)$ and Methane $\left(\mathrm{CH}_{4}\right)$ have been the main focus in climate change calculations and discussions, the potential impact of Nitrous Oxide $\left(\mathrm{N}_{2} \mathrm{O}\right)$, which is also generated from Waste Water Treatment Plants (WWTPs) is now gaining increased prominence. $\mathrm{N}_{2} \mathrm{O}$ is one of the radioactive gases considered by the Intergovernmental
Panel on Climate Change (IPCC) for as one of the greenhouse gas emissions Inducing Climate Change (IPCC, 2013). Process of optimization for minimizing NGHG release from WWTPs is ongoing among manufacturing Industries in Lagos (LSME, 2012). Waste management poses a big challenge to environmental management in the State and is one of the sectors with significant contribution to climate change globally through emissions of greenhouse gases into the atmosphere. Decomposition of organic and inorganic wastes from dumpsites and landfills release GHGs such as methane, nitrous oxide and carbon-dioxide. Poor management of industrial waste matters such as polythene and other plastics, uncontrolled discharge of oily wastes (chemicals and liquid hydrocarbons such as grease, oil and other petroleum products) and poor management of wastes from the shipping industry in coastal areas also result in emission of methane and carbon-dioxide.

\section{AIR POLLUTION AND LAGOS CLIMATE CHANGE: THE RISKS}

Climate change and air pollution are closely related. Apart from the effects on human health, atmospheric gasses $\left(\mathrm{CO}_{2}\right)$ affects the Earth's climate by trapping energy and preventing the escape of heat on the earth surface from escaping, leading to variability in climatic conditions (EPA, 2011). Unique features of Lagos State such as high and rapidly increasing population, the plat topography, extensive coastal areas and high water table which in some areas of Lagos Island is less than $0.15 \mathrm{~m}$ from the surface, are predisposing factors that further increase the State's vulnerability to climate change impacts (LSME, 2012). Recent research by the University of Hawaii as reported in the Washington Post by (Bernstein, 2013) showed that Lagos climate may undergo unprecedented change by 2029 . The report also indicated that the current trends of greenhouse gas emissions will shift the climate change of most places in the world (including Lagos) beyond documented extremes. A report released by Lagos State. Ministry of the Environment (2012), revealed expected climate change in Lagos; these reports showed a temperature increase of $0.04^{\circ} \mathrm{C}$ per year from now until the 2046-2065 period, wetter climate that will result in annual rainfall and longer rainy seasons and extreme weather and heat days. The expected impacts of these extreme events are: Loss of livelihoods, loss of land to the sea due to sea level rise, loss of physical infrastructure, loss of ecosystems and biodiversity, pollution of surface and groundwater, increased risk of water-borne diseases, chronic respiration illness, 
corrosion, acid rain and damage of crops. Environmental effects of this phenomenon will be discussed under the following: The sea rise and flooding, health risks and loss of biodiversity.

\subsection{Impacts of Climate Change on Lagos Water Sector}

Lagos State has the longest stretch of Nigeria coastline at about $180 \mathrm{~km}$ long, constituting $20 \%$ of the country's coastline. The coastline is characterized by a rich diversity of flora and fauna including fish, coral reefs and mangrove forests. Wetland habitats are integral components of coastal fisheries and provide critical a spawning and nursery grounds for many marine and fresh water organisms. Estuarine and lagoon fisheries provide livelihood for many coastal communities. The importance of water resources to the society cannot be overemphasized. Water is used for various purposes such as cooking, irrigation, drinking, bathing; it is linked to various sectors of the economy; the health, energy, agriculture and industries. Its uses are inexhaustible. Because of many uses and applications, this sector is under continuous pressure and demands from both public and private sectors and will indeed be faced with depletion in time due to climate change (IPCC, 2013). Water resources availability for mankind is threatened all over the world due to continuous drought, desertification and flooding occurrences. In Lagos, groundwater resources, the alternative source of water supply that people largely depend on, have been reported to have depleted due to climatic changes. The salt water intrusion due to sea level rise and flooding serves a major pollution to this source of water, even the freshwaters. It is expected that the river flows will decrease because of evaporation while runoff will increase due to high rainfall which will impact on the water quality.

Lagos, due to its unprecedented population increase and urbanization processes, is being affected negatively by many environmental factors, particularly climate and ecosystems changes. These seem to be inevitable and unavoidable phenomena in Nigeria's most populous city. The climatic temperature in Nigeria is expected to increase as predicted by Intergovernmental Panel on Climate Change (IPCC). IPCC (2000) discovered a fast increase/rise in temperature with $0.3-0.6^{\circ} \mathrm{C}$ over Africa in 20th century and possibility of rise between $1.4^{\circ} \mathrm{C}$ and $5.8^{\circ} \mathrm{C}$ in the next 100 years. Ojo (1987) estimated changes in climate conditions in Nigeria in the 19th century and an increasing average temperature of about 0.3 to $0.6^{\circ} \mathrm{C}$ through the 21 st century. Evidences from the Nigerian Meteorological Agency (NIMET) revealed a significant increase in air temperature in Lagos, Kano, Calabar and some other cities in the country (Idowu et al., 2011; Onyenechere, 2010). The assessment by NIMET showed a decrease between 1941 and 2000 in annual rainfall by $2-8 \mathrm{~mm}$ across the country, a long-term temperature increase in most parts of the country, excluding Jos area where low temperatures were recorded (BNRCC, 2011).

A climate change downscale for Nigeria developed by (BNRCC, 2011) under A2 scenario projected a temperature increase of 0.04 to $4.5^{\circ} \mathrm{C}$ from 2011 through to 2100; the rainfall showed variability across the country, with a wetter climate in the south and drought in the northeast (Fig. 3). Recently, projections of the imminent occurrence of floods and flash floods in places like Lagos and other coastal cities will definitely affect Nigeria's drinking water supply. With these developments, the frequent occurrences of heavy downfalls and pronounced droughts events are expected in some regions. As a result, the country is faced with present and future challenges in its water sector due to shortage of water in some parts and salinity and pollution in other parts. The implication of this on Lagos and its environs is obvious because it is the most populated and highly industrialized state, the frequent occurrences of water shortage and pollution resulting from flooding. Therefore, it is obvious that climate change will impact on water availability and its geographical and seasonal distribution (Halliru and Umar, 2012); this of course inhibits Nigeria's capacity to meet the targeted Millenium Development Goals on water availability (Akpor and Muchie, 2011). Lagos residents are more vulnerable to the projected climate impact with many people living and industries established in coastal areas.

\subsection{Sea Level Rise and Flooding in Lagos}

Accumulations of greenhouse gases in the atmosphere over the years can result in temperature rise and unusual precipitation, which may result sea level rise in coastal areas. According to IPCC, a prediction of a one meter rise in sea level in $21 \mathrm{st}$ century resulting from glacier and ice sheet melting with thermal expansion will be caused by the rising in temperature. The potential of sea level rise to alter the living conditions of the half of the world's population in the coastal zones and the constant risks of flooding have been reported (Townsend, 2002). In recent times, the extreme and unusual rains in Lagos have resulted into flooding, especially in the coastal regions of the state. It is one of the major environmental hazards now being faced by the mega city, threatening lives and 
properties (Oshodi, 2013). According to The Guardian (Editor, 2012), between July and October, 2011 alone, at least 7 major floods were witnessed killing about 30 people and destroying many properties. Also in 2012, heavy rains caused an unusual flooding that displaced thousands of people from their homes, with inhabitants of Islands and poorly constructed structures badly affected (Oshodi, 2013) (Fig. 4). Extreme weather and climate events in the State are increasing in frequency and intensity as a result of climate variability and climate change. Storms and floods are the primary weather and climate related disasters in the State. These are often associated with loss of life, property and infrastructure damage, loss of GDP and other socio-economic setbacks. This is posing a big challenge to Disaster Risk Management (DRM). Projected impacts of future climate change are likely to be more devastating, hence the need to develop robust DRM system.

Flooding in Lagos and environs is becoming a yearly disaster, which can be attributed to the changing climate and also the high vulnerability of the communities, especially those living on the flood plain. Lagos is hosts to vast areas of coastal communities that are prone to flooding. The landscape of Lagos, with many people living below the twometer elevation and the continuous increase in the population without adequate infrastructures to meet with the insurgence of the flooding makes it vulnerable to flooding (French et al., 1995). The low lying nature of islands and the surroundings makes them vulnerable and it is of great concern when sea level rises or there is heavy rainfall.

\subsection{Health Risks}

Air pollution, particulate matter, especially the smaller particles, has harmful effects on human health. Cases of respiratory diseases and even death have been reported in Lagos (Ogunbi et al., 1978; Olowoporoku et al., 2012). An epidemiological study by (Olowoporoku et al., 2012) showed a growing evidence of relationship between air pollution and mortality, hospital admissions for respiratory or cardiovascular disease and an associated increased risk of myocardial infarction in Lagos.

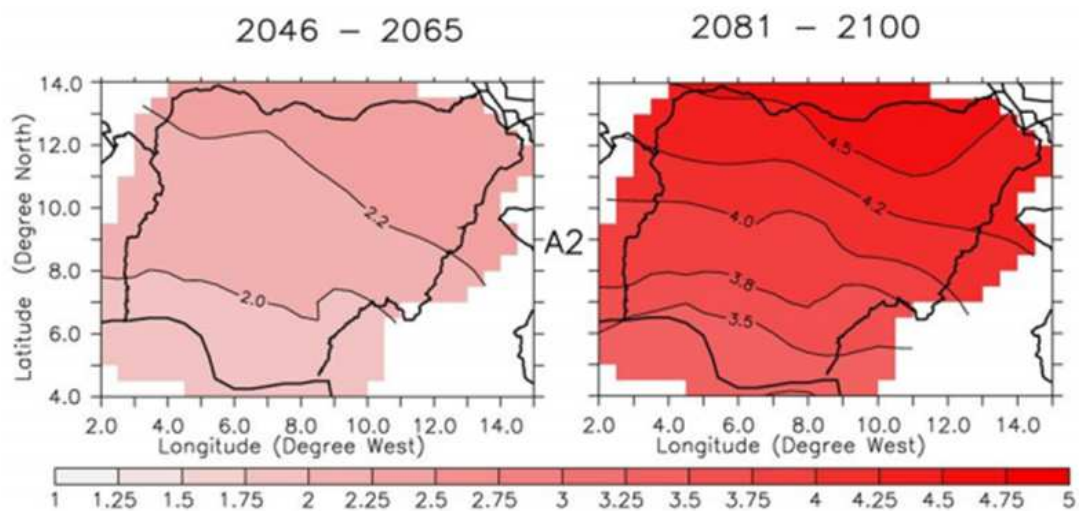

Fig. 3. Projected changes in temperatures in Nigeria under IPCC A2 Scenario by (BNRCC, 2011)

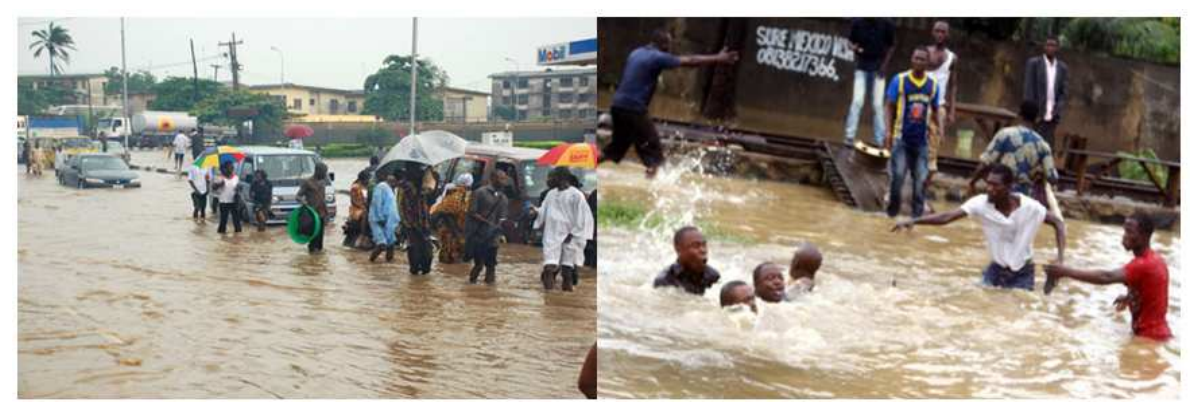

Fig. 4. June, 2012 flooding in some parts of lagos state (sources: Scan news (information for development) and the vanguard newspaper) 
The study revealed that the increasing rate of heart diseases and infections in most hospitals is as a result of the pronounced air pollution in the state. Apart from the direct effects of the air pollution, the flooding consequence has a lot of influence on human health. Infectious water-borne diseases from the water-borne resulting from flooding are well pronounced worldwide. Flooding is the lead cause of water-related mortality and can result in vector associate problems such as the increase in mosquito populations, which translates into more mosquito-related diseases (Kazama, 2012). The effect of water pollution from the industries (Sujaul et al., 2013) and their health challeges are overwehelming. It is obvious that in Lagos, many cases of malaria are being witnessed due to the insurgence of water-borne disease from several occurrences of flooding.

\subsection{Loss of Biodiversity}

Air pollution, although not mostly considered in biodiversity conservation and planning, it has been described as one of the major factors that influences it losses. Lovett et al. (2009) clearly showed that all ecosystems types are affected by the air pollution; it affects both the aquatic and terrestrial habitats, which are expected to be of benefits to man. Biodiversity in Lagos is mostly affected by the insensitive landuse changes due to the increase in population. The continual generation of air pollution contributes to acidification of coastal waters and indirectly affects the underground water. The salinity of Lagos surface and underground water due to pollution has been reported (Olufemi et al., 2010); this has great effect on human and the aquatic organisms.

Loss of wetlands and pollution of water resources can have a devastating effect on the State's biodiversity resource and livelihood options, yet these are some of the potential impacts of climate change on the State,s wetlands. The State's wetlands coverage has reduced fromabout $53 \%$ of the total landmass in 1965 to about $2 \%$ at present, mainly due to human activities and increasingly due to climate variability and climate change. Coastal wetlands are particularly vulnerable to sea level rise. IPCC's projection that up to $33 \%$ of the world's wetlands could be converted to open waters by sea level rise (IPCC, 2007) should be a serious concern to Lagos State.

\section{OVERCOMING THE CHALLENGES}

Air pollution's reduction and eradication have been one of the major global environmental change issues in the world; this is because of its contribution to the large percentage of the global variations of climate, which has been a threat to many communities today. Efforts to address the issue of air pollution globally through global and local environmental policies have proved abortive and complex, mostly due to lack of funds (Puppim de Oliveira, 2011). The solution to air pollution cannot be addressed on a global scale, but need a holistic approach to achieve a reasonably reduction of greenhouse gas, whereby reducing the dangerous effects of the climate change. Based on the several predictions of the negative impacts of the climatic conditions of Lagos, there is need for a holistic but sustainable approach to solving the problem.

According to IPCC (2000), adaptation is the adjustment in natural or human systems in response to actual or expected climatic stimuli or their effects, which moderates harm or exploits benefits. There is need for quick adaptation and resilience plans against the current and future climate and ecosystems changes in Lagos water sector in order to cope with the imminent hazards. In this study, management of the risks in this sector will balance between the software (early warning systems) and hardware (mitigation, adaptation and resilience). This is necessary because continuous adaptation and resilience building without information on the magnitude and the time of extreme events and also means of reducing or mitigating its causes (greenhouse gases), will amount to a fruitless efforts. Hence, three-way approachis hereby proposed for climate change risk managements in water sector in Lagos state, Nigeria.

\subsection{Assessment of Lagos State Govt. Policies and Plan of Action on Pollution Prevention and Mitigation Against Climate Change}

A balance between mitigation and adaptation is necessary to be able to cope with the future climate events in Lagos State and Nigeria as a whole. Nigeria's contributions to global greenhouse gas emissions are high due to its rapid population growth and energy consumptions. Although it is a great challenge for a country whose economy largely depends on fossil fuels to cut down its carbon emission, it becomes highly imperative to mitigate in order to avoid future hazards. Lagos as a subset state contributes to large percentage of these emissions.

The following greenhouse reduction strategies are proposed:

- Improvement of energy efficient performance of new and existing buildings: Excessive utilizations of energy in every household must be regulated and reduced. Development of innovative technology such as fuelsaving and low energy appliances will help to counter balance the increase in fuel consumption. Several 
initiatives in area of renewable energy such as solar power panels in both private and public buildings, wind energy generation and the use of biomass need to be adopted, with a gradual shift from the nonrenewable sources of energy, which are major sources of air pollution (Puppim de Oliveira, 2011)

- Sustainable eco-friendly transport systems and vehicle emissions monitoring. Introduction of effective rail systems will reduce frequent traveling with fossil fuel-powered vehicles

- Sustainable and efficient land use

- Energy diversification, promoting the development and the use of renewable energy instead of the fossil fuel being currently used

- Effective waste management through recycling. Quite substantial amounts of gases are generated by the wastes at landfill sites; these contribute to some percentages of air pollution in Lagos and its environs. For example, the dumpsite at Ojota, Lagos is one of the largest in the city, accounting for several tons of wastes, which are often openly incinerated. This kind of unhealthy practice immensely contributes to the pollution state of the city. The solution to this is to stop burning wastes at dump sites and adopt waste separation and recycling techniques and also seize the opportunity to generate electricity

Introduction of carbon tax and air pollution policy: Although environmental policies in many nations and local governments globally are confronted with implementation challenges, yet the need to establish an effective one is very imperative to mitigate the effects of climate change and reduce the looming danger on the Lagosians. Air policies drafting should incorporate the government and non-governmental agencies, local and state governments, industries and academics and the communities. The policy should put in place the measures against use of various sources of pollution: Limits industries pollution sources and encourage a sustainable energy generation (renewable energy sources); introduction of green economy (tree planting); infrastructures standards; land use and tenure transportation policy; waste generation and recycling; role of individuals in ensuring a safe atmosphere and comprehensive disaster response plan. Establishment of a Clean Air Act is non-negotiable in an industrialized city like Lagos. This will place air pollution limits on industrial units, such as power and chemical plants. The law will allow individual local governments to have stronger and effective pollution management.
Carbon Sequestration: This is the capturing and storage of greenhouse gases from different sources such as fossil fuel power, industrial and household carbon generation, thereby preventing the release of $\mathrm{CO}_{2}$ into atmosphere. It is mostly done through: Tree planting and Underground Storage. Tree planting has been advocated as a sure way of capturing Carbon-dioxide and the subsequent effects on climate change. Lagos State biodiversity has been greatly affected due to urbanization and population increase; this is a big challenge to its survival as far as environmental challenge arising from greenhouse gases is concerned. Tree planting campaign should be intensified throughout the city and every local government and household should be encouraged to plant trees. Underground Storage is a geoengineering technique, which involves the injection of $\mathrm{CO}_{2}$ into geological formations and stored there to prevent its release to the atmosphere.

\subsection{Early Warning Systems, Risks and Vulnerability Assessments}

Members of the public should be aware of the quality of the air they breathe in order to take necessary actions. The essential step in tackling this problem and ensuring environmental quality conservation is by efficiently monitoring potential air pollutants at local dimension. Continuous monitoring and reporting of air quality data with emphasis on its spatial dimension is very essential in a large city like Lagos. The use of satellite technology coupled with ground based instruments to gather real-time and continuous data respectively are needed to ensure air quality assessment. The use of telecommunication gadgets and mobile devices such as cellular phones with remote sensing applications can provide dynamic, temporally and spatially precise information of these pollutants (Kelly et al., 2012). The assessment must include identification of the source of pollution, its spatial distribution and the future trend; this will help policy makers to take decisive actions for remedy. More importantly, people will be prepared to adapt and modify their behavior toward generation of greenhouse gases and also avoid its consequences. As for flood events, a computer-based, flood early warning system should be developed for Lagos State. There is need to assess the level of people's vulnerability to the effects of air pollution and the risk involved before air management plans. Most times, air pollution vulnerability is caused by poverty, disease, lack of education and poor living conditions. The vulnerability assessment will include: Air pollution sources; air pollution levels; air pollution potential; level of community awareness; observations; 
people's perceptions and actions (Makri and Stilianakis, 2008). Understanding of the level of risk involves both quality and quantity that will assist in making a wellinformed decision on prevention and mitigation. The health risks and the amount of greenhouse gases emitted must be quantified to understand the extent of the risks. Apart from health risk assessments, sea level rise and flood forecasts with flood risk assessment should be done. With earth observation systems, sources of pollution and their spreads can be detected early for effective adaptation plans by the stakeholders.

Most developing countries are suffering from the effects of climate change due to lack of information. In Nigeria, many communities are often not aware of the changing climatic conditions and their impacts. Farmers keep wondering why the variability in rainfall pattern in some parts of the countries because they do not have understanding of the current trends in climate and ecosystems changes. There is need to improve on scientific understanding of the climatic conditions in Nigeria, especially in the areas of observational data collection, management and exchange of information on current and historical climate change and variability. Frequent climate change modeling and downscaling from the global scenarios to Nigeria will be of great help to understand present and future climate situations; this will go a long way in informing the society of impending hazards on different sectors. Apart from this, information dissemination through the Geographic Information Systems, media, mobile phones and other Information Technology sources will create awareness. Understanding of the risks and vulnerability of the current and future extreme events of the governments, people and all stakeholders will reduce the potential impacts of the climate change, especially those who live in coastal regions of the country, Lagos in particular.

\subsection{Risk Assessesment Through Satellite Technology}

Assessing the contribution of Lagos to global cimate change can be done through effective utilisation of remote sensing technology. The use of remote sensing and satellite technology as means of assessing the concentrations of greehouse gassess is highly important as prevention and mitigation measures. Satellites is useful in observing the conditions and processes of the atmosphere and can provide information about the state of the climate at any given time and scale (Yang et al., 2013). Example of carbon moniroing system is the National Aeronautics and Space Administration (NASA)'s caborn monitoring satellites initiated in 2010. The system is capable of assessing the levels carbon in the atmosphere, which be a significant prevention, mitigation and adaptation measures against climate change (Yang et al., 2013).

\subsection{Stakeholders' Collaboration}

The idea of single approach by a single arm of government in an effort to counter the effects of air pollution has not yielded expected results. Lagos State comprises local governments saddled with functions to effectively administer the affairs of the people and their environment. The starting point in the drafting and implementation of the zero environmental pollution policies must begin with a unanimous collaboration between the two governmental organs of the states. Partnership with other stakeholders such as the industries, federal governments, communities, academic and research institutions (scientists, social and human specialists) and relevant international organizations is needed to establish working principles and modalities to collectively reduce greenhouse gas emission. The issue of pollution should not be left to the local government alone to tackle. The capability of each local government to implement air pollution policies varies; in fact, quite a large number of them cannot effectively carry out air pollution policy. Hence state, national and international agencies should pull resources together to equip the local governments with organizational capability and instruments for implementation (Puppim de Oliveira, 2011).

\subsection{Creation of Awareness and Education}

Ignorance of actions often results in very dangerous consequences to any community. It is worthy of note that there are many Lagos dwellers today that are not aware of the consequences of their actions, especially in the area of fossil fuel burning, the use of household generators and so on. Awareness program must be initiated and be taken to the grassroots to cut across every stratum of city inhabitants, irrespective of age, status and the living standard. Public education and capacity development education through local governments and other stakeholders (companies and industries) should be carried out in order to enlighten the people on the effects of air pollution and possible ways of avoiding it.

\subsection{Adaptation and Resilience Strategies in Lagos Water Sector}

Nigeria is presently adopting a reactive measure in its adaptation and resilience plan. These have not been helpful for the vulnerable people and the communities. Most times efforts to curb flooding in both urban and rural areas come after the events have taken place. This business-as-usual syndrome must be replaced with 
proactive steps in ensuring best mitigation and adaptation practices before the arrival of extreme events. The most important question to be answered is: How do people, especially the vulnerable Lagos people cope with and adapt to extremes events in the water sector? The need to explore and couple both indigenous traditional knowledge and technology is very imperative. The Government of Lagos State must be proactive in this regard and take drastic steps in ensuring a system viable and strong enough to withstand the effects of climate change on its water sector. Various adaptation measures in water sector against climate and ecosystems changes have been suggested by many scholars (Onyenechere, 2010; BNRCC, 2011), which can be adapted for Lagos case.

Impacts of flooding and droughts on water resources (fresh water, coastal water) and distribution due to the variability in rainfall resulting from climate change are great and necessary measures must be put in place to ensure safety of the people and access to clean and safe water. These include:

- Early warning and prediction of climatic conditions through simulations and modeling: This is probably one of the proactive ways of adapting and building resilience to climate change extreme events. Through early warning and predictions, most vulnerable communities can adjust to the changes maybe through relocation and adopting local methods for survival

- Building and construction of dikes, levees and dams to prevent extreme flooding events. Based on the knowledge of the coming events such as sea level rise and excessive rainfall that may result in rainfall, dikes and levees should be built along sea and river banks to prevent excessive run off

- Creation of dams and diversion of river flow can be of help to effective sources of irrigation for agricultural use

- Landuse change policies

- Stakeholder involvement and River basin governance; (vi) Increase in the usage of irrigation will reduce runoff and downstream flow (Eheart and Tornil, 1999)

- Water recycling: A technology that uses and re-uses water as being adopted by some developed countries can be applied

- Groundwater exploration as an alternative to surface water

- Upgrading of slum and adaptive coastal management: The improvement of Lagos slums is one of the most recommended ways to reduce extreme inequality in Lagos (Gandy, 2006). The slum areas in Lagos are along the coastline (Ijora, Yaba-Ebutemeta and some parts of Ketu) which are mostly affected by flood during extreme rain or, as it has been projected, sea level rise. The need to raise the standard of living, especially infrastructural building, is very important to build the resilience of the people to subsequent flooding. The current practice of land reclamation without adequate technology in place should be stopped and avoided. Rather, the Lagos State Government should concentrate on building structures to guard against flood resurgence from the impact of climate change

- Building of embankments/dykes on the Lagos Island should be encouraged; and

- In case of water pollution, water quality survey on both surface and underground should be done. This will ascertain the level of pollution on waters

The water sector is very much associated with agriculture. Northern Nigeria is expected to experience droughts while flooding is expected in the south. The following are suggested as possible adaptation strategies to cope in this sector within the country:

- Early warning systems should be provided to farmers on weather situations. This will prepare them for agricultural best practices

- Application of local knowledge by farmers such as moisture conservation techniques when rains fall and crop diversification can be of great help. Cultivation of short-season millet during drought year rather than maintaining the usual cropping mixtures of crops that can be affected during drought is the key adaptation measure. This will ensure a successful cultivation under drought situations

- Introduction of genetically-modified foods

- Adoption of improved agricultural systems for both crops and livestock: Intensifying crop and livestock production, planting of native vegetation cover

- Planting of flood resistant crops

- Rain water capture for irrigation

As earlier mentioned, water pollution resulting from flooding and sea level rise will bring about sickness and diseases; this will affect both human and aquatic ecosystem. Climate change influences the distribution of schistosomiasis, a water-related parasitic disease with aquatic snails as intermediate hosts (IPCC, 2007). Lagos 
State health sector is very weak in terms of health care facilities, especially in rural communities. This makes the people more vulnerable to vector borne diseases and sickness. Adaptation should begin with risks and vulnerability assessments. Statewide survey on the vulnerable communities should be carried out using various tests and indicators. Improving health care systems, which are extended to rural areas, is needed to help those infected with sicknesses and diseases. The need to introduce water treatment technology in all the nation's water corporations to ensure water quality before supply to both rural and urban areas is very important. Introduction of effective sanitation policies throughout the country will enhance the adaptability of the people.

Major concern in the energy sector of Nigeria as affected by water is the projected drought events, which will likely reduce the volume of water in dams and rivers. The hydropower generation from water sector will definitely be affected. Invariably, the consequence of this on Lagos will be well pronounced due to its high consumption of electricity. Adaptation to this challenge will be integrated watershed management and creation of more dams. Alternate sources of energy such as waste power production, biomass energy, solar and wind energy can be another diversified ways of power generation in the face of extreme climatic drought conditions.

\section{CONCLUSION}

Air pollution contributes to the present global environmental changes as it is currently being experienced in Lagos. Many lives have been lost to flood and health diseases resulting from this phenomenon. The involvement of all stakeholders in the fight against the most important contributing agent of climate change is very imperative with a view to proffering an effective solution. Both National and state governments, together with the agencies, industries and academics should empower local communities with necessary tools and resources to reduce the level of greenhouse gases. Although the challenge of climate change on Lagos' water sector is huge, a quick and proactive intervention through collaborative efforts of the governments (national, state and local), private sectors and communities can provide a strong resistance against future impacts. Central to all the aforementioned adaptation strategies are: The involvement of all stakeholders both in mitigation and adaptation to climate change; acknowledgement and enhancement of traditional knowledge by local people, especially farmers in adaptation to extreme weather conditions; financial support to rural areas and integrated water management and allocation. Apart from these, education, both formal and informal, must be adopted in the creation of awareness on climate change and the need for every citizen to be conscious of his/her carbon footprints.

\section{REFERENCES}

Akanni, C.O., 2010. Spatial and seasonal analysis of traffic-related pollutant concentrations in Lagos Metropolis, Nigeria. African J. Agric. Res., 5: 12641272. DOI: 10.5897/AJAR09.253

Akpor, O.B. and M. Muchie, 2011. Challenges in meeting the MDGs: The nigerian drinking water supply and distribution sector. J. Environ. Sci. Technol., 4: 480-489. DOI: 10.3923/jest.2011.480.489

Bernstein, L., 2013. D.C. Climate will shift in 2047. researchers say; Tropics will feel unprecedented change first. The Washington Post. Health and Science.

BNRCC, 2011. National adaptation strategy and plan of action on climate change for Nigeria (Naspa-Ccn).

Crowley, T.J., 2000. Causes of climate change over the past 1000 years. Science, 289: 270-277. DOI: 10.1126/science. 289.5477 .270

Editor, G., 2012. Taming the floods in Lagos. The Guardian.

Eheart, J.W. and D.W. Tornil, 1999. Low-flow frequency exacerbation by irrigation withdrawals in the agricultural midwest under various climate change scenarios. Water Resour. Res., 35: $2237-$ 2246. DOI: 10.1029/1999WR900114

Emordi, E.C. and O.M. Osiki, 2008. Lagos: The 'Villagized' City. Inform. Society Justice, 2: 95- 09.

EPA, 2011, Climate change report, Environmental Protection Agency (EPA).

French, G.T., L.F. Awosika and C.E. Ibe, 1995. Sealevel rise and Nigeria: Potential Impacts and Consequences. J. Coastal Res., 14: 224-242.

Gandy, M., 2006. Planning, anti-planning and the infrastructure crisis facing metropolitan lagos. Urban Stud., 43: 37-396. DOI: 10.1080/00420980500406751

Halliru, S. and D.U. Umar, 2012. Climate Change and Rural Water Supply Planning in Nigeria. In: Climate Change and the Sustainable Use of Water Resources. Filho, W.L. (Ed.), Springer, Berlin Heidelberg, ISBN10: 978-3-642-22265-8, pp: 305-315. 
Idowu, A.A., S.O. Ayoola, A.I. Opele and N.B. Ikenweiwe, 2011. Impact of climate change in Nigeria. Iranica J. Energy Environ., 2: 145-152.

IPCC, 2000. Good Practice Guidance and Uncertainty Management in National Greenhouse Gas Inventories.Working Group 1, National GHG Inventories Programme, IGES.

IPCC, 2007. Climate change 2007: Impacts, adaptation and vulnerability.

IPCC, 2013. Working group I contribution to the IPCC fifth assessment report climate change: The physical science basis.

Kotkin, J. and W. Cox, 2013. The World's FastestGrowing Megacities. Forbes Magazines. Availableat.

Kazama, S., 2012. A quantitative risk assessment of waterborne infectious disease in the inundation area of a tropical monsoon region. Sustainability Sci., 7: 45-54. DOI: 10.1007/s11625-011-0141-5

Kelly, F., G. Fuller, H. Walton and J. Fussell, 2012. Monitoring air pollution: Use of early warning systems for public health. Respirology, 17: 7-19. DOI: 10.1111/j.1440-1843.2011.02065.x

Lovett, G., H.T. Timothy, C.E. David, E.G. Stuart and F.B. Jack et al., 2009. Effects of air pollution on ecosystems and biological diversity in the eastern united states. Ann. Acad Sci., 1162: 99-135. DOI: 10.1111/j.1749-6632.2009.04153.x

LSME, 2012. Carbon dioxide emission management in Nigerian Mega Cities: The case study of lagos. UNEP, Urban and Environment. Lagos State Ministry of Environment.

Makri, A. and N. Stilianakis, 2008. Vulnerability to air pollution health effects. Int. J. Hyg Environ. Health, 211: $\quad 326-236$.

DOI: 10.1016/j.ijheh.2007.06.005

MAN, 1991. Yearly economic review. Lagos. Manufacturer Association of Nigeria.

Ogunbi, O., H.O. Fadahunsi, I. Ahmed, A. Animashaun and S.O. Daniel et al., 1978. An epidemiological study of rheumatic fever and rheumatic heart disease in lagos. J. Epidemiol. Commun. Health, 32: 68-71. DOI: 10.1136/jech.32.1.68

Ogunnowo, C.O. and K.A. Aderogba, 2006. Urban climate and thermal comfortability: A case study of Lagos Metropolis. J. Environ. Cons. Res., 1,: $113-127$.
Ojo, O., 1987. Rainfall Trends in West Africa, 19011985; the influence of climate change and climate variability on the hydrologic regime and water resources. IAHS Publications, 168: 37-42.

Olowoporoku, A., J. Longhurst and J. Barnes, 2012. Framing Air Pollution as a Major Health Risk in Lagos, Nigeria. In: Air Pollution XX, Brebbia, C. and J. Longhurst (Eds.), Southampton and Boston: WIT Press, ISBN-10: 9781845645823, pp: 479-486.

Olufemi, A.G., O.O. Utieyin and O.M. Adebayo, 2010. Assessment of groundwater quality and saline intrusions in coastal aquifers of lagos metropolis, Nigeria. J. Water Resourc Protect., 2: 849-853. DOI: 10.4236/jwarp.2010.210100

Onyenechere, E.C., 2010. Climate change and spatial planning concerns in Nigeria: Remedial measures for more effective response. J. Hum. Ecol., 32: 137148.

Oshodi, L., 2013. Flood management and governance structure in Lagos, Nigeria. Regions Magazine, 292: 22-24. DOI: 10.1080/13673882.2013.10815622

Phillips, T. and C. Horwood, 2007. Tomorrow's Crises Today: The Humanitarian Impact of Urbanisation. 1st Edn., Illustrated, Nairobi, Kenya, OCHA/IRIN, ISBN-10: 9211319641, pp: 112.

Puppim de Oliveira, J.A., 2011. Why an air pollution achiever lags on climate policy? the case of local policy implementation in mie, Japan. Environ. Plann. A, 43: 1894-1909. DOI: 10.1068/a43240

Raheem, A.M.O.A. and F.A. Adekola, 2011. Air pollution: A case study of ilorin and lagos outdoor air, indoor and outdoor air pollution. Department of Chemistry, University of Ilorin, Ilorin,

Sujaul, I.M., M.A. Hossain, M.A. Nasly and M.A. Sobahan, 2013. Effect of industrial pollution on the spatial variation of surface water quality. Am. J. Environ. $\quad$ Sci., $\quad$ 9: 120-129. DOI: 10.3844/ajessp.2013.120.129

Townsend, M., 2002. Environmental refugees. Ecologist, 32: 22-25.

Yang, J., P. Gong, R. Fu, M. Zhang and R. Dickinson, 2013. The role of satellite remote sensing in climate change studies. Nature Climate Change, 3: 875-883. DOI: $10.1038 /$ nclimate 1908 